\title{
Temperature Prediction Model for Controlling Casting Superheat Temperature
}

\author{
Natasha GUPTA and Sanjay CHANDRA \\ Research \& Development Division, Tata Steel, Jamshedpur-831001, India. \\ E-mail: natashagupta@tatasteel.com, sanjayc@lot.tatasteel.com
}

(Received on April 13, 2004, accepted in final form on June 30, 2004)

\begin{abstract}
A temperature prediction model has been developed for controlling the casting superheat temperature. For ease of implementation, the model is intentionally made simpler having a combination of a one dimensional heat transfer model and a simple regression model. The model is based on the fact that the BOF temperature of the liquid steel along with the bath cooling behaviours controls the aimed casting superheat temperature. Starting with the steel liquidus temperature and calculating the required steel temperature backwards throughout the process line gives the targeted BOF tap temperature. The on-line picking up of actual data helps the model to predict for the next stage more accurately in forward direction. Based on the predicted steel temperature, plant operators can take any necessary corrective action like additional ladle heating and extra/reduced argon stirring to ensure the aim final ladle/tundish temperatures at the casting are achieved.
\end{abstract}

KEY WORDS: BOF; finite difference; ladle furnace; on line purging; regression; superheat; temperature; tundish.

\section{Introduction}

\subsection{Aim of the Study}

Temperature of liquid steel supplied to continuous casting is very crucial for high quality products. If the temperature is too high, the adverse effect of centreline segregation can increase or, in the extreme case, a breakout can occur. If the temperature is too low, nozzle clogging and, subsequently, steel contamination with macro-inclusions can occur. In the extreme case, the low temperature even leads to freezing in the nozzle. Since the last point where temperature can be adjusted is usually far away from the caster, it is important to properly predict what might be the temperature loss from this point to the caster, and what might be the temperature loss during casting.

This study has been taken up for reducing the quality defects of the direct route (BOF-On line purging stationSlab caster) heats of LD2\&SC, Tata Steel, India which were due to high/low superheat at caster. The last controllable temperature for a direct route heat has been the BOF vessel itself. This is followed by an on-line purging (OLP) during which the temperature can be reduced by continuing purging operation. Then the ladle exits from the station and is transferred to caster. The existing set of general rules to predict the temperature loss to match the predicted temperature did not satisfy high quality steel requirements in the shop. They were causing excessive deviation and, subsequently, frequent steel degrades, especially due to clogging. As a result, the shop had a tendency to run average superheat temperature at the caster on the hot side. This practice, along with concerns about cracking and centre line segregation, had the additional negative effect on refractory wear.

In an effort to reduce a deviation between the actual and aim superheat temperatures, a comprehensive model of liquid steel temperature loss has been developed and implemented in the shop practice.

\subsection{Modelling of Heat Loss}

When liquid steel is held in a ladle, heat loss occurs by conduction through the ladle wall and bottom, radiation and convection from the top surface of metal which is in contact with the atmosphere. Several mathematical models ${ }^{1-22)}$ have been developed to predict the liquid steel temperature in the ladle with the elapse of time. A detailed search of literature was undertaken to study the modeling approach used by other researchers. The findings of literature survey are summarized in Table 1.

As shown in Table 1, only a few models are available with a two-dimensional approach. Austin et al. ${ }^{12)}$ used the ADI-method, based on finite differences, and Fredman et

Table 1. Summary of literature survey.

\begin{tabular}{|l|c|}
\hline \multicolumn{1}{|c|}{ Model Approach } & References \\
\hline 1-D model with finite difference scheme & $1-11$ \\
\hline 2-D model with finite difference / finite element method & $12 \& 13$ \\
\hline 3-D CFD model with TEMPSIM \& PHOENICS packages & $15-16$ \\
\hline Used PHOENICS package for stratification, holding \& casting period. & $17-22$ \\
\hline
\end{tabular}


$a l .{ }^{13)}$ used the finite element method for solving the two-dimensional dynamic heat conduction equation in the lining geometry, simultaneously with the energy balance equation for the perfectly mixed liquid steel. Radiation heat transfer above the slag surface was coupled with both the thermal state of the lining and the energy balance. Hence, radiation, convection as well as conduction in the lining were considered at each time step in the solution of the energy balance for the molten steel. Such computationally demanding models are suitable mainly for off-line simulations. Work of Shklyar ${ }^{8)}$ and Fredman ${ }^{14)}$ are primarily concerned with online simulation. Addes and Sabol $^{23}$ ) have developed a process model based on statistical approach to control the casting superheat.

The present paper describes an attempt to model the complex steel making and casting phenomena by a combination of one-dimensional heat transfer model and a statistical model. The heat transfer differential equations have been discretized through finite difference method and nonlinear regression has been used to capture the hidden pattern in voluminous data.

\section{Identification of Causes}

The BOF tapping temperature of the liquid steel along with the bath cooling behaviours controls the aimed casting temperature. For the assessment and pre-calculation of the cooling behaviour of steel from the BOF converter upto casting, all points of losses need to be considered. During tapping, the pouring liquid stream losses heat to the ambience and to the refractory of the converter mouth. During holding, transport and casting of the filled ladle the mean temperature of the steel decreases on account of different modes of heat losses. Liquid steel loses heat in the ladle mainly due to transient conduction through the ladle lining, convection and radiation from the ladle top and melting of ferroalloys added in the ladle. Heat loss from the top of the liquid steel depends on the depth of slag cover, cover powder type and its distribution and usage of a ladle lid. The temperature drop due to melting of ferroalloys depends on the quantity of ferroalloy additions and their chill factor.
The heat loss due to conduction through refractory lining is greatly affected by the temperature distribution in ladle lining. This process is dependent on the thermal status of the ladles, which is in turn dependent on the conditions during the return transport of the empty ladles from the continuous caster. The losses and important factors are summarised in Table 2.

In addition, due to the natural convection there is a downward flow of ìcoldÅEsteel along the ladle wall. Different patterns of drainage flow may cause the outlet steel to be taken from the cold bottom layers or from warmer layers. When the steel is teemed into the tundish, it loses heat by conduction to the tundish wall and the slag. The behaviour of the temperature at the outlet of the tundish is influenced by the transport time as well as by steel flow phenomena, e.g. mixing and shortcut flows (Fig. 1).

Thus, phenomenon such as slab cleanliness, centreline segregation, nozzle clogging, breakout, achievable casting speed and tundish life, etc., are influenced by the amount of superheat possessed by the liquid steel in the tundish/mould. Many quality and productivity limitations

Table 2. Various heat losses throughout the teelmaking process and the important factors.

\begin{tabular}{|l|l|}
\hline \multicolumn{1}{|c|}{ Losses } & \multicolumn{1}{c|}{ Important factors } \\
(wall and bottom) & \\
\hline $\begin{array}{l}\text { Convection and radiation loss through } \\
\text { the liquid steel top }\end{array}$ & Slag cover, cover powder type \& its \\
distribution, ladle lid
\end{tabular}

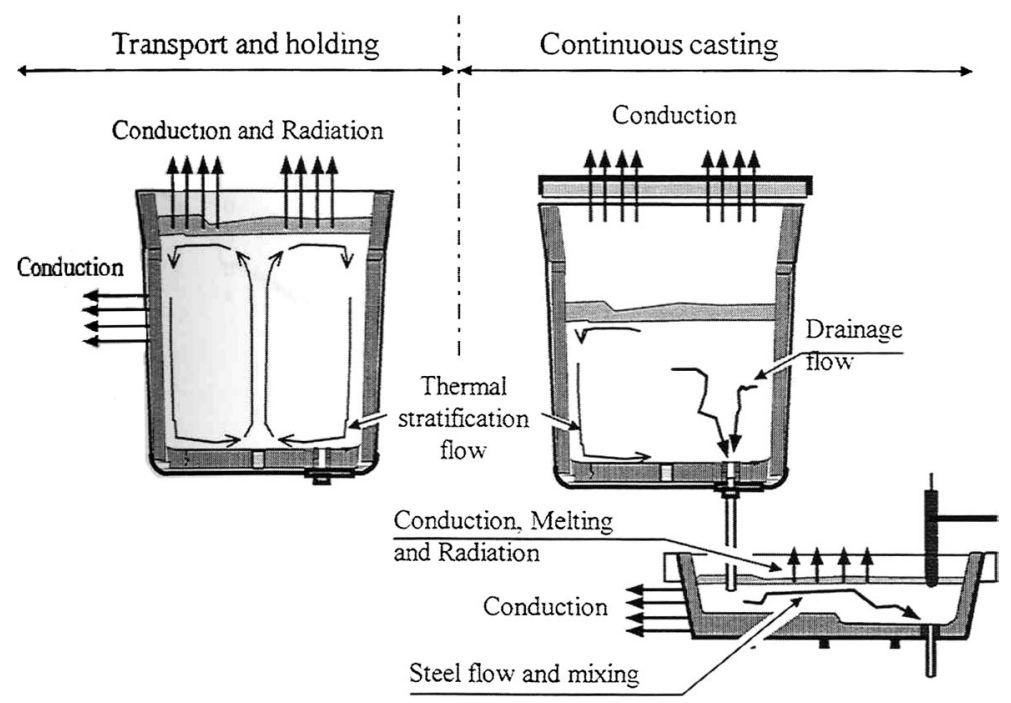

Fig. 1. Summary of the mechanisms during holding and casting which have an influence on the steel temperature in the tundish. 
of a caster are, therefore, linked to the liquid steel temperature in the ladles. Hence, to carefully control the degree of superheat, it is very important to predict the loss of energy from the heat at all process steps from the converter to the casting machine. The control of steel temperature in the ladle has become very important as it impacts directly on the tundish/mould temperatures.

Beside the thermal state of the lining, many other variables effect heat loss such as the extent of refractory wear and skull, ladle holding time, stirring time, nature and extent of ladle treatment (alloying etc.), slag amount and composition as well as the casting time.

The availability of a mathematical model that can incorporate all these process details so as to predict the temperature of the liquid steel at the various stage of its processing is thus paramount.

\section{Mathematical Model}

The cycle of a direct route that a ladle undergoes at LD2\&SC is shown in Fig. 2. For estimation of the targeted BOF tap temperature for the right casting temperatures, the steel liquidus temperature is the starting point and the required steel temperature should be calculated backwards throughout the process line (Fig. 3). The temperature losses at the various stages between the BOF converter and the continuous caster need to be taken into account in order to determine the required tapping temperature. The following

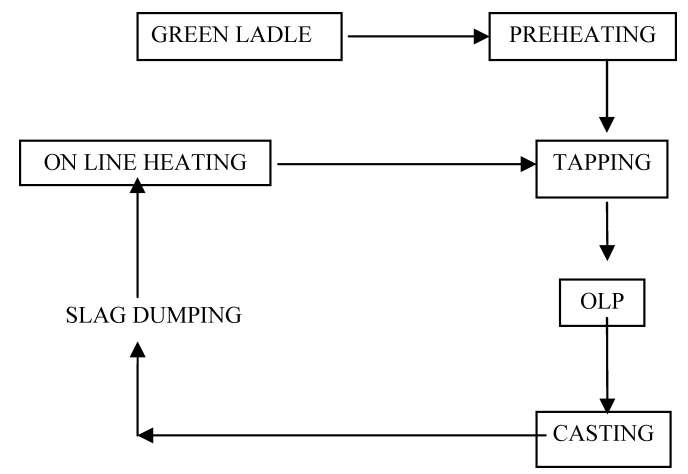

Fig. 2. The cycle of ladles at LD\#2\&SC for Direct Route.

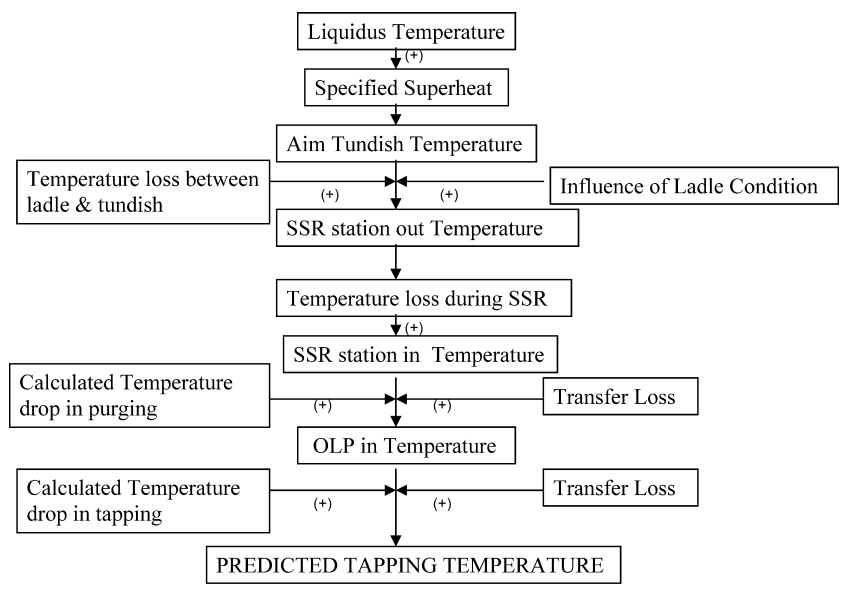

(SSR : Secondary Steel Refining)

Fig. 3. Steps for construction of model for estimation of targeted taping temperature. equation can be used:

$$
\begin{aligned}
T_{\text {steel }}= & T_{\text {liq }}+\Delta T_{\text {superheat }}+\Delta T_{\text {tundish }}+\Delta T_{\text {ladle-tundish }} \\
& +\Delta T_{\text {ladle(t) }}+\Delta T_{\text {alloy }}+\cdots
\end{aligned}
$$

To capture the phenomena from tapping to casting, a combination of one-dimensional heat transfer model and a statistical model has been developed for computing heat losses from the ladle to enable calculations to be carried on-line. The one-dimensional heat transfer model has been dealt in this paper as sub-model I, where as the sub-model II is dealing with the statistical model. We will later discuss why the statistical model would become the choice of calculation instead of a finite difference heat transfer model for certain stage.

\subsection{Sub Model I: One Dimensional Heat Transfer Model}

\subsubsection{Model Description}

Thermal condition of a ladle changes continuously with change in its hot face temperature. Therefore, transient heat transfer analysis is considered for the computation of temperature in the multi-layer refractory lining of ladles and to cover up the process from an empty ladle waiting for tapping up to on-line purging. The finite-difference technique is employed to discretise the governing differential equations in cylindrical coordinates. Heat losses through the side wall and the bottom of the ladle are computed separately. A lumped mass analysis is employed for the computation of the liquid steel temperature.

Ladles in Tata Steel typically carry 130 tonnes of liquid steel. Relevant properties of the ladle used in the computation are listed in Table 3.

The ladle is considered to be cylindrical and structurally symmetrical (Fig. 4). For sake of simplicity, the steel contained therein is assumed to be a perfectly stirred liquid with uniform temperature. Even though this assumption is known to be unjustified - mainly because of thermal stratification of the melt - the degree of the temperature gradient in the molten steel upto OLP can be considered minor. Afterwards, the stratification has been tried to address by a polynomial relation in the sub-model II.

The used governing heat flow equations and boundary

Table 3. Thermal and physical properties of ladle wall and

\begin{tabular}{|c|c|c|c|c|c|}
\hline \multirow{3}{*}{ Ladle } & \multirow{3}{*}{ Layers } & \multicolumn{3}{|c|}{ Thermal } & \multirow{2}{*}{$\begin{array}{l}\text { Specific } \\
\text { Heat }\end{array}$} \\
\hline & & Thickness & Conductivity & Density & \\
\hline & & $\mathrm{m}$ & $\mathrm{W} / \mathrm{mK}$ & $\mathrm{Kg} / \mathrm{m} 3$ & $\mathrm{~J} / \mathrm{kg},{ }^{\circ} \mathrm{C}$ \\
\hline \multirow[t]{4}{*}{ Side Wall } & Tar dolo & 0.15 & 6.4 & 2920 & 1000 \\
\hline & $42 \%$ Alumina & 0.032 & 1.2 & 2400 & 1130 \\
\hline & LC-70 & 0.1 & 1.7 & 2720 & 1100 \\
\hline & Steel shell & 0.028 & 52 & 7800 & 552 \\
\hline \multirow[t]{4}{*}{ Bottom Wall } & Mag carbon & 0.2 & 7.6 & 2950 & 1150 \\
\hline & $80 \%$ Alumina & 0.04 & 1.8 & 2800 & 1080 \\
\hline & LC-70 & 0.11 & 1.7 & 2720 & 1130 \\
\hline & Steel shell & 0.081 & 52 & 7800 & 552 \\
\hline
\end{tabular}
bottom refractories as used in Tata Steel. 


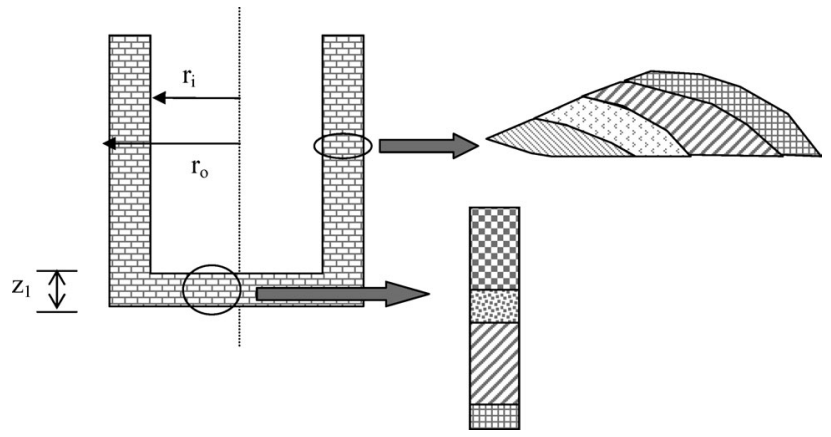

Fig. 4. Schematic diagram of ladle.

conditions for the wall and bottom of the ladle are presented below:

Side wall: for $r_{\mathrm{i}} \leq r \leq r_{\mathrm{o}}$,

$$
1 / r \partial / \partial r(r k \partial T / \partial r)=\rho C_{\mathrm{p}} \partial T / \partial t
$$

Bottom: for $0 \leq z \leq z_{1}$,

$$
\partial / \partial z(k \partial T / \partial \mathrm{z})=\rho C_{\mathrm{p}} \partial T / \partial t
$$

Boundary conditions:

(a) Outer surface of the ladle:

$$
\begin{aligned}
& \text { for } \left.r=r_{\mathrm{o}}, \quad k \partial T / \partial r=h\left(T_{\mathrm{s}}-T_{\mathrm{a}}\right)+\sigma \varepsilon F\left[T_{\mathrm{s}}^{4}-T_{\mathrm{a}}^{4}\right)\right] \\
& \left.z=z_{1}, \quad k \partial T / \partial z=h\left(T_{\mathrm{s}}-T_{\mathrm{a}}\right)+\sigma \varepsilon F\left[T_{\mathrm{s}}^{4}-T_{\mathrm{a}}^{4}\right)\right] \ldots \ldots
\end{aligned}
$$

(b) Inner surface of the ladle:

$$
\text { for } r=r_{\mathrm{i}} \text { and } z=0, \quad T=T_{\mathrm{L}}
$$

The heat transfer coefficient is obtained for free-convection from a long vertical cylinder. The general boundary conditions as well as some specific boundary conditions are applied accordingly as required for different stations. Since the liquid steel in the ladle looses heat through the ladle wall and bottom refractories via conduction and through top surface via convection and radiation, the total heat loss is calculated as a summation of each of the individual heat losses at each of the following stations.

\section{Ladle Heating}

Tapping into a cold ladle is always undesirable; it adversely affects the refractory lining in addition to causing a significant drop in the liquid steel temperature. Hence, ladle heating is very crucial for proper control of superheat of liquid steel. Usually a green (new) ladle is heated by a vertical gas burner till it attains the desired temperature. For predicting the temperature of the refractory lining with respect to the heating time, boundary conditions at the inner surface of the ladle is obtained from the literature. ${ }^{24)} \mathrm{A}$ mixture of coke oven gas and LD gas with $20 \%$ excess air has been considered as the combustion gas. When the ladle is recycled once then the initial profile of the refractory lining is calculated taking into account the life of the ladle and its turn around time.

\section{Ladle Waiting before Tapping}

The hot empty ladle loses heat in the turn around time. During this period the ladle loses heat from the outer surface by natural convection and radiation as already mentioned. Additionally, the inner hot face of the ladle loses heat by radiation only.

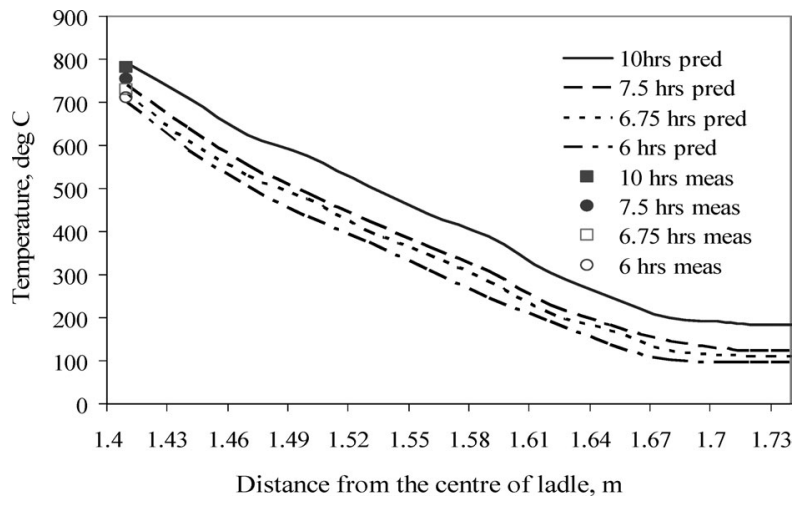

Fig. 5. Measured and predicted temperature in wall after heating.

\section{Tapping}

Since the starting point of the model is the tapping temperature of the liquid steel in the converter, the heat losses in liquid steel are considered from this stage.

Loss of heat from the liquid steel during tapping, by the conduction through the converter lining is computed from the correlation proposed by Omotani et al. ${ }^{3)}$

$$
Q_{\text {cond }}=1.6 A_{\text {conv }}\left(K_{\mathrm{r}} \rho_{\mathrm{r}} c_{\mathrm{pr}} / \Pi\right) 1 / 2\left(t_{\mathrm{m}}-t_{\mathrm{rc}}\right) \bar{\mho}_{0}
$$

Heat loss from the liquid stream falling into the ladle is quantified as per the recommendation of Henzal and Keverian. ${ }^{25}$ ) During the tapping of the liquid steel alloy, cold additions to liquid steel are made causing changes in the liquid steel temperature. The chill factors ${ }^{26)}$ for ferro-alloys are incorporated to calculate the changes in the temperature occurred due to their additions.

\section{On Line Purging}

At the OLP station, the liquid steel is purged with argon gas for homogenisation of the temperature and the composition. The modes of heat losses are conduction through refractory lining, loss/gain due to additions, and radiation loss from the top surface. The presence of skull at the ladle bottom is incorporated in the model to quantify the heat loss from the liquid steel due to skull. It was found through plant trials that the average drop in liquid steel temperature due to thin skull is $8.8^{\circ} \mathrm{C}$ and due to thick skull is $11.4^{\circ} \mathrm{C}$.

\subsubsection{Validation}

The mathematical model for the new ladle heating is tested with the actual data observations. In the plant, the hot face temperature of the ladle is measured by a radiation pyrometer as indicated in Fig. 5. The accuracy of the measurement was $\pm 20^{\circ} \mathrm{C}$ (actual $\sim$ measured). The prediction of the hot face temperature from the model is found to be very close to actual measurements. The effect of delay on the temperature of the wall lining is shown in Fig. 6. This delay is between the end of preheating and start of tapping.

Finally, the steel temperature prediction in OLP after synchronizing all the previous activities is validated against plant data and is found to be within $\pm 5^{\circ} \mathrm{C}$ from the actual value for $66 \%$ of the heats and within $\pm 7^{\circ} \mathrm{C}$ for $97 \%$ of the heats (Fig. 7).

\subsubsection{Results of Sub Model I}

A. The validation up to OLP strengthened the fact that purging has great impact on the homogenisation of the bath 


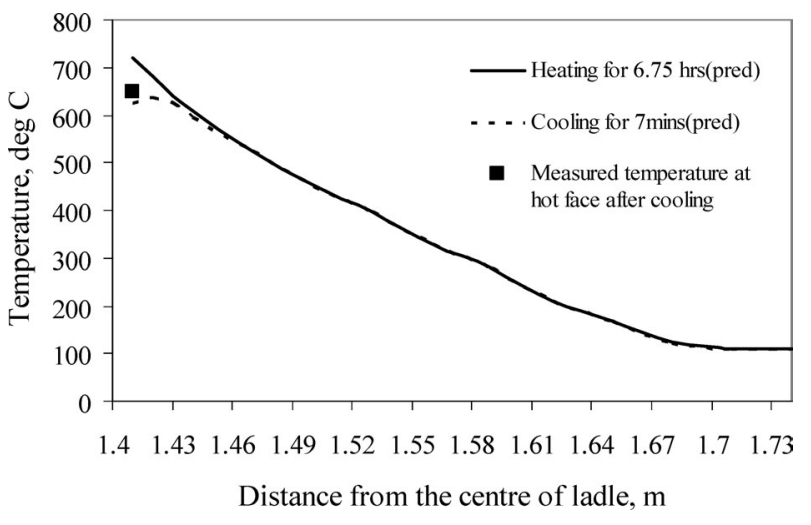

Fig. 6. The wall temperature profile after cooling.

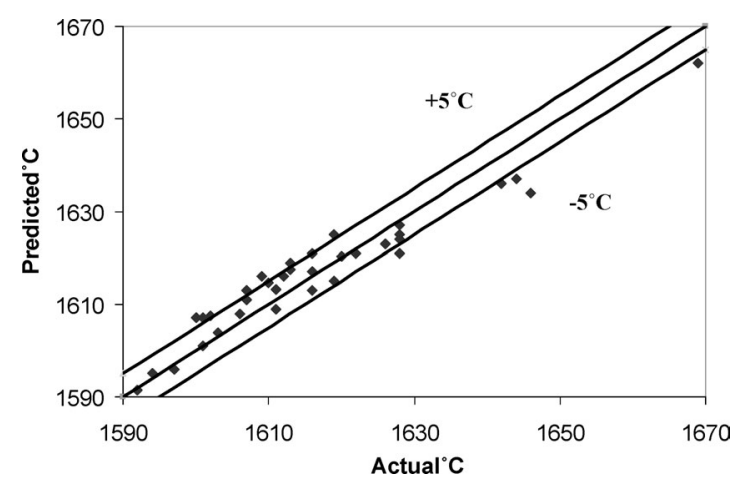

Fig. 7. Validation of liquid steel temperature at OLP.

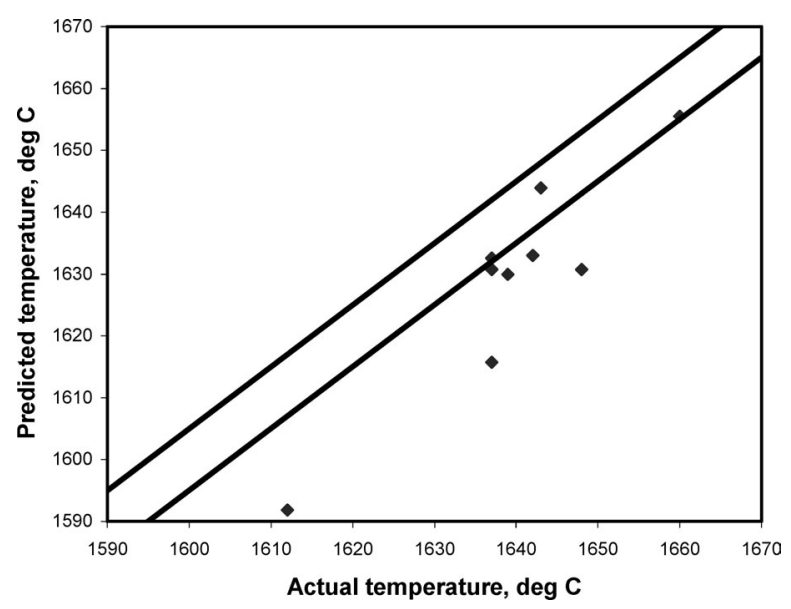

Fig. 8. Actual and predicted OLP temperature before purging.

temperature and thus on the matching of the prediction with plant measurements because the thermal stratification was not assumed in the calculations of the model. The argon flow rate usually varies from 400 to $600 \mathrm{~L} / \mathrm{min}$ in the plant. The prediction is within the range for those heats which were well purged at OLP. It is found that purging less than 2 min leaves the bath non-homogenised. In actual measurement this non-homogenised condition gives the temperature of a stratified layer whereas the model calculates the mean temperature based upon all parameters of influence. This hypothesis is cross checked with special trials in the plant made at OLP. One temperature was just taken as the ladle came in OLP and another after the full purging. The model was run to predict temperature of the liquid bath for both of these timings with and without the purging effects. The re-

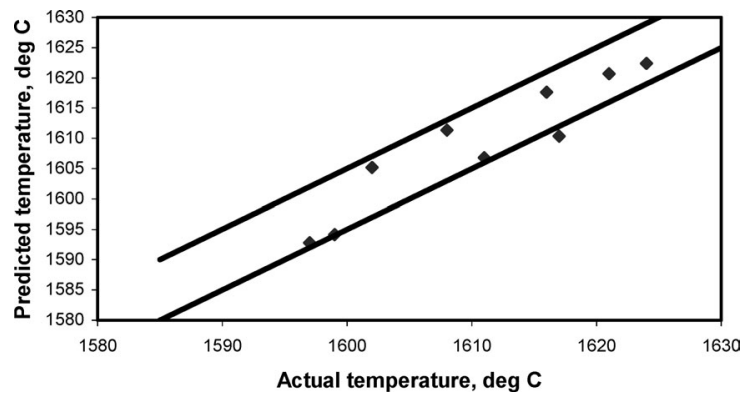

Fig. 9. Actual and predicted LOP temperaturte after pruging.

Table 4. Findings from the sub model I.

\begin{tabular}{|c|c|c|}
\hline Station & Percentage & Activities and Losses \\
\hline \multirow[t]{4}{*}{$\begin{array}{l}\text { Preheating ladle } \\
\text { with CO \& LD }\end{array}$} & $\begin{array}{c}70 \% \text { of input } \\
\text { energy }\end{array}$ & $\begin{array}{l}\text { Lost with the combustion } \\
\text { exhaust gases }\end{array}$ \\
\hline & $23-25 \%$ & $\begin{array}{l}\text { Increases the energy content of } \\
\text { the refractory }\end{array}$ \\
\hline & $6 \%$ & $\begin{array}{l}\text { Conducted through the } \\
\text { refractory walls }\end{array}$ \\
\hline & $0.3-0.5 \%$ & Is stored in the ladle lid \\
\hline \multirow{4}{*}{$\begin{array}{l}\text { While tapping } \\
\text { (assuming no } \\
\text { alloy addition) }\end{array}$} & $40 \%$ & $\begin{array}{l}\text { Conduction loss through } \\
\text { refractory lining of the ladle }\end{array}$ \\
\hline & $25-27 \%$ & Radiation loss in ladle \\
\hline & $16-17 \%$ & $\begin{array}{l}\text { Conduction loss through mouth } \\
\text { refractories of vessel }\end{array}$ \\
\hline & $16-17 \%$ & Stream loss \\
\hline \multirow{4}{*}{$\begin{array}{l}\text { While on-line } \\
\text { purging } \\
\text { (assuming no } \\
\text { alloy addition) }\end{array}$} & $70 \%$ & $\begin{array}{l}\text { Conduction loss through } \\
\text { refractory lining }\end{array}$ \\
\hline & $30 \%$ & $\begin{array}{l}\text { Radiation loss from the top } \\
\text { surface }\end{array}$ \\
\hline & \multicolumn{2}{|c|}{ Residual skull in ladle } \\
\hline & $\begin{array}{c}\text { Nil } \\
8.75^{\circ} \mathrm{C} \\
11.4^{\circ} \mathrm{C}\end{array}$ & $\begin{array}{l}\text { If clean } \\
\text { If thin } \\
\text { If thick }\end{array}$ \\
\hline
\end{tabular}

sult appeared as was expected. The temperature measured before purging and the model prediction were not matching though the same heat after sufficient purging was showing good match with the model prediction afterwards (Figs. 8 and 9). Thus the idea of getting a homogenised bath, only after at least $2 \mathrm{~min}$ of purging done is reinforced through the model.

B. The model is run for several heats and the contribution of different modes of heat loss at each station up to OLP is summarised (Table 4). A large fraction of the input energy given by coke oven and LD gas to heat the ladle at ladle heating station is lost with the combustion exhaust gases and only one fourth is consumed to increase the heat 


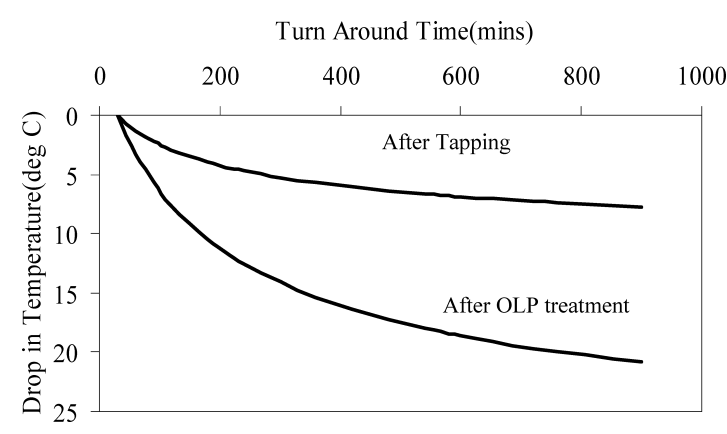

Fig. 10. Effect of Turn around time on liquid steel temperature.

content of the refractory bricks. During tapping, one-third of the total heat loss is contributed by the losses through the vessel refractories and the pouring stream of the liquid steel. At OLP station, the radiation loss from the top surface is responsible for $30 \%$ of the total heat loss where as the $70 \%$ loss occurs through conduction into the refractory linings.

C. Typically

a) $55-60 \%$ of the total heat is lost through the ladle wall refractory,

b) $15-20 \%$ through the ladle bottom, and

c) $25-30 \%$ is lost through slag.

D. It is observed that the hot face temperature immediately starts decreasing due to continuous heat loss and the internal temperature in the brick layer remains relatively higher. A relation of turn around time with drop in liquid steel temperature has also been established (Fig. 10).

E. The one-dimensional heat transfer model was tried further to calculate the heat loss during ladle teeming and during holding period before teeming, but the plant validation was not found encouraging. It becomes difficult to exactly model the teeming without getting into complex fluid dynamics or rigorous view factor calculations.

\subsection{Sub Model II: Statistical Model}

\subsubsection{Model Description}

Developing a 2-dimensioanal or 3-dimensional heat transfer and fluid dynamics model to cover the complex phenomena of holding and teeming are not supportive for an on-line prediction model, as these model would be lengthy and time-consuming. If a fast calculation is needed, e.g., for production control, analytical equations are of interest. ${ }^{23)}$ With the view of analytical/statistical solutions for holding and teeming period, followings are the subjects of concern:

- The thermal status of the ladle and its effect on the decrease of the steel temperature while holding the liquid steel in the ladle.

- The thermal stratification and drainage flow in the ladle, and their effect on the temperature in the outlet steel stream.

- The mixing and steel flow in the tundish and their effect on the temperature at the outlet end during teeming.

Holding period

When the homogenised bath waits for the teeming to start, the held bath gets thermally stratified in some layers. Estimates from literature ${ }^{27)}$ indicate that if the cooling rate of liquid steel is constant, there is a constant rate of in- crease of the thermal stratification. This rate is approximately proportional to the cooling rate and the cooling rate during the holding period is a function of holding time, slag thickness and the ladle thermal status. Thus the thermal stratification can be expressed as:

\section{Thermal stratification $=f$ (slag thickness, ladle thermal status and holding time)}

\section{Slag Thickness and Holding Time}

It has been observed that during holding period significant temperature stratification occurs in the melt with the thick slag layer, and the degree of stratification increases with the holding time. However, due to the insulating cover effect, the heat loss through the top is minimal and the average temperature of the melt doesn't decrease much. For a thin layer of slag, resulting in appreciable heat loss from the top, the bulk of the melt in the ladle is well mixed due to the strong buoyancy driven convection currents. This, in turn, results in temperature homogenization of the melt. However, due to appreciable heat loss through the top, the average temperature of the melt decreases continuously, and the trend continues during pouring of the melt from the ladle. In a study done by Chakraborty and Sahai, ${ }^{28)}$ temperature during pouring of the teem stream declines by only 5 to $10^{\circ} \mathrm{C}$ over $47 \mathrm{~min}$ of casting time for an insulating slag layer whereas, for a thin slag layer the temperature of the pouring stream declines by about $45^{\circ} \mathrm{C}$ from the start of teeming of the melt to the end of the casting period.

In LD2\&SC, the slag thickness for a direct route heat varies from 40 to $60 \mathrm{~mm}$ which can be put under the single slag category, i.e. thin, to avoid the complexity of slag depth measurement. Heat loss through the top slag layer is estimated from the correlation proposed by Szekely et al. ${ }^{29)}$ The study of heat loss and thermal stratification with respect to the varying slag thickness gives some hint for the drainage flow and temperature drop pattern during teeming for same kind of heat but different thickness of slag cover which varies as per the plant condition.

\section{Ladle Thermal Status and Holding Time}

The thermal stratification increases as the initial ladle wall temperature decreases, and is drastically influenced by the ladle thermal state of ladle. When a green ladle comes to the shop, it is preheated sufficiently for minimum of $8 \mathrm{~h}$ for changing the refractory condition from cold to high heat content condition. For a circuitous ladle, the turn around time (after end of teeming to start of tapping) plays the lead role for the ladle wall temperature before tapping. The effort on the shop floor is being put over to reduce the turn around time.

It has been observed that the history of the thermal stratification at a certain initial thermal ladle state can be very well represented by a fourth-order polynomial ${ }^{30)}$ as follows:

$$
\Delta T_{\mathrm{s}}(t)=a_{0}+a_{1} t+a_{2} t^{2}+a_{3} t^{3}+a_{4} t^{4}
$$

Where $\Delta T_{\mathrm{s}}(t)$ is the temperature difference between the top and bottom layer of liquid bath due to thermal stratification. The coefficients $a_{0}$ to $a_{4}$ depend on the initial thermal states of the ladle.

The mean steel temperature decreases with time because of heat loss into refractories and to the ambient from the 


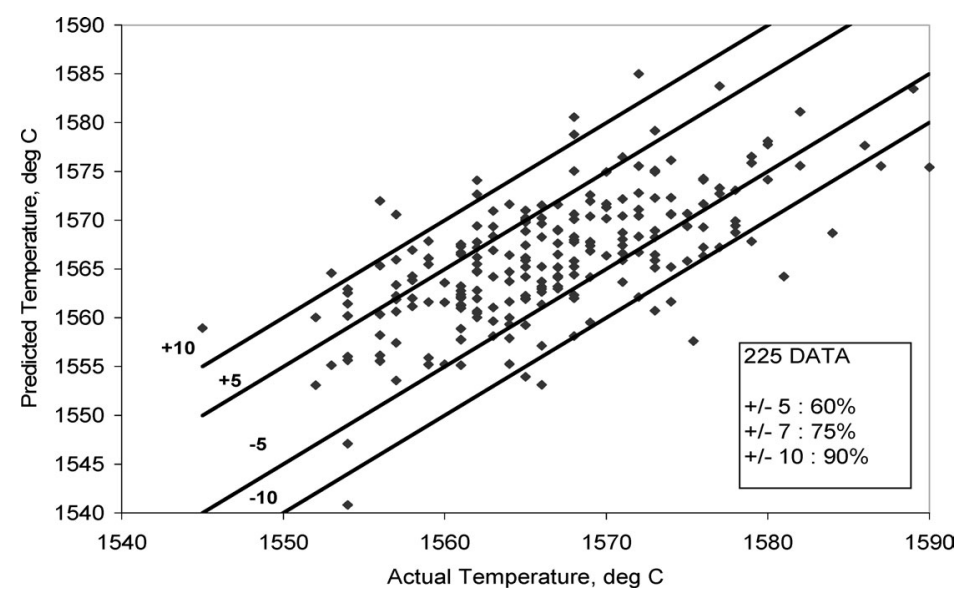

Fig. 11. Predicted $v s$. actual first tundish temperature.

slag surface. Austin ${ }^{27)}$ suggests that the rate of development of thermal stratification is proportional to the cooling rate of liquid steel. Thus, similar to thermal stratification, the mean steel temperature with time can again be well represented by a fourth-order polynomial depending upon the initial ladle thermal state.

$$
T_{\mathrm{s}, \mathrm{avg}}(t)=T_{\mathrm{int}}-\left(a_{0}+a_{1} t+a_{2} t^{2}+a_{3} t^{3}+a_{4} t^{4}\right)
$$

Where $T_{\text {int }}$ is the initial uniform temperature of liquid steel before holding period. Here, the OLP-out temperature is taken as $T_{\text {int }}$, which is considered as homogenised after sufficient amount of purging.

$T_{\mathrm{s}, \text { avg }}(t)$ gives the mean steel temperature in ladle, the first reactor, after holding it for time $t$. The pouring of liquid steel from ladle into tundish starts in ' $t+1$ ' time so the first temperature of liquid steel in tundish is definitely the same temperature calculated by Eq. (7) at ' $t+1$ ' time. But the temperature of that poured liquid in tundish is influenced by the temperature history of the existing liquid steel in this second reactor. The liquid steel already present in tundish has a mixing effect with the new steel coming in and the resulted temperature will be a function of $T_{\mathrm{s} \text {,avg }}(t)$ and existing steel temperature $T_{\text {past }}$.

Thus, the Eq. (7) of the first temperature $T_{\text {tun1 }}$ of the liquid steel in the tundish is modified

$$
T_{\text {tun } 1}=f\left(T_{\text {s,avg }}(t), T_{\text {past }}\right)
$$

Since the validity of this expression holds for a particular ladle thermal status, it is necessary to capture all possible combinations of the turn around time and the ladle lifethe two key factors responsible for a ladle thermal condition. A suitable relation is found by doing regression over large number of data.

$$
\begin{aligned}
T_{\text {tun } 1}= & 180.912+0.019 \mathrm{LL}-0.012 \mathrm{TAT}+0.358 T_{\text {past }} \\
& +0.631 T_{\text {OLP-out }}-40.428 t+3.173 t^{2}-0.107 t^{3}+0.001 t^{4}
\end{aligned}
$$

Where, $t=$ holding time ( $\mathrm{min})$.

This expression is used in the statistical model and validated against the plant data. The $R^{2}$ value of the regression coefficient is 0.73 and the standard error is $\pm 4.2^{\circ} \mathrm{C}$ with $95 \%$ level of confidence that means, the $67 \%$ of the prediction of first tundish temperature lies in the range of $\pm 4.2^{\circ} \mathrm{C}$, where as $95 \%$ and $99 \%$ of the prediction fall in the range of $\pm 8.4^{\circ} \mathrm{C}$ and $\pm 12.6^{\circ} \mathrm{C}$ respectively.

\section{Teeming Period}

As fluid flows out of the nozzle from a stratified ladle its temperature at the exit point reflects the liquid withdrawal pattern within the ladle. The ladle during teeming is usually lid-covered. The study ${ }^{27)}$ shows that the temperature curves during drainage generally take the form:

$$
T_{\mathrm{m}}=a+b t+c \cdot e^{-d t}
$$

Where, $t$ : draining time.

This correlation represents a short-term exponential decay with a long term linear trend and is highly supported by the casting pattern of LD\#2 slab casting also. The subsequent temperatures $T_{\text {tund(t) }}$ of the liquid steel in the tundish are found to be well represented by a function of time and the temperature $T_{\text {tun1 }}$ (discussed earlier) attained by the poured liquid steel in the tundish after few minutes of teeming. In practice, this is the temperature measured in the tundish after approx. $10 \mathrm{~min}$ of the ladle opening.

$$
T_{\text {tund(t) }}=a+T_{\text {tun } 1}+b_{1} t+b_{2} t^{2}+b_{3} t^{3}+b_{4} t^{4}
$$

The actual equation with known coefficients is as follows:

$$
\begin{aligned}
T_{\text {tund(t) }}= & 170.53+0.891 T_{\text {tun } 1}-0.721 t+0.031 t^{2} \\
& -0.007 \mathrm{E}-01 t^{3}+5.26 \mathrm{E}-06 t^{4}
\end{aligned}
$$

Where $t=$ casting time ( $\mathrm{min})$.

This expression is found to efficiently explain the pattern of the subsequent temperature drop during teeming. The $R^{2}$ value of the regression coefficient for this expression is 0.81 with a standard error of 5 i.e. $67 \%, 95 \%$ and $99 \%$ of the prediction lie in the range of $\pm 5^{\circ} \mathrm{C}, \pm 10^{\circ} \mathrm{C}$ and $\pm 15^{\circ} \mathrm{C}$ respectively.

\subsubsection{Validation}

To validate the result of holding period, the model is run for 225 data and $60 \%, 75 \%$ and $90 \%$ of the predictions are found in the range of $\pm 5^{\circ} \mathrm{C}, \pm 7^{\circ} \mathrm{C}$ and $\pm 10^{\circ} \mathrm{C}$ (Fig. 11). The relation of teeming period is validated with 300 data and highly encouraging results are obtained. Figure 12 for the prediction of subsequent casting temperature shows that $75 \%, 88 \%$ and $95 \%$ of the predicted value were within $\pm 5^{\circ} \mathrm{C}, \pm 7^{\circ} \mathrm{C}$ and $\pm 10^{\circ} \mathrm{C}$. Superior results are expected in due course of on-line operation.

Several other factors are considered to make the relation further better, explained below. 
Temperature of the Existing Liquid Steel

Temperature of the existing liquid steel was considered similarly as was done for the first tundish temperature to see the impact over the stream temperatures but no improvement was observed. The result supports the science behind it. The temperature of the existing liquid steel has a primary influence when the new liquid steel poured into the tundish. With time, the old liquid is replaced by the coming new liquid and assuming good mixing of old and new liquid, the first temperature of steel plays the overleading role in the state of the subsequent temperatures. But incorporating the volume of left over liquid steel of last heat to calculate the mixing effect will give undoubtedly improved results. This work is currently being done.

\section{Drainage Rate}

The effect of drainage on the bulk flow pattern is expected to be quite significant. In LD2\&SC, the drainage rate is usually kept fixed at $1.1 \mathrm{~m} / \mathrm{min}$ but the throughput changes with the variation in the slab section size. The effect of the slab section size for different throughput was examined for improving the relation but the factor was found to be neutral (neither improvement nor worsening) over the results.

Turn around Time

The performance of the Eq. (10) was subjected under different turn around time ranges but again not much of change is found on the subsequent tundish temperatures.

\subsection{Temperature Prediction Model (TPM)}

The two sub-models are integrated and a GUI is incorporated into the model. Once the thermal status of ladle in terms of turn around time is known, the drop in steel tem-

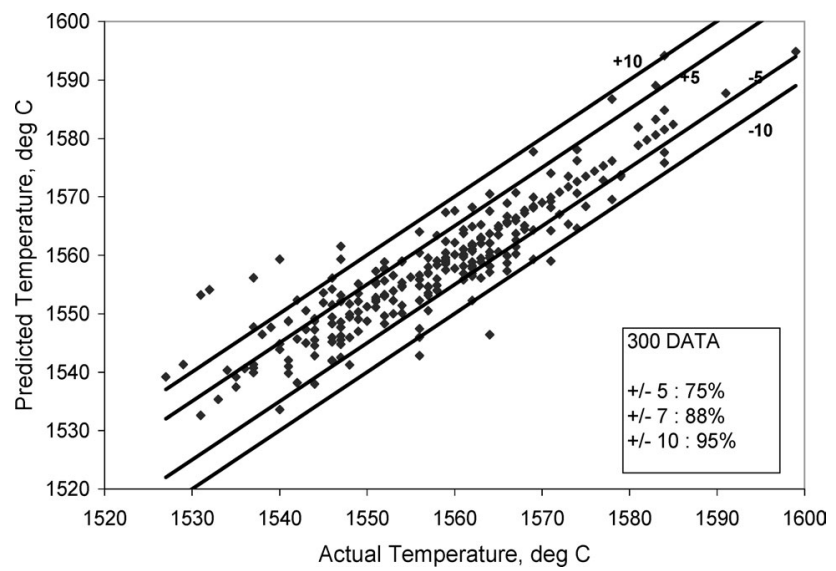

Fig. 12. Predicted $v s$. actual subsequent tundish temperature. perature with time in ladle can be estimated using the TPM model. The developed model calculates temperatures in both-forward (Fig. 13) and backward (Fig. 14) - direction. Using fed data, it produces results for operators at all strategic points. The first prediction of the liquid steel temperature path for a heat is generated at the start of tapping. For a given grade and section size the optimum final aimed ladle steel temperature prior to casting is generally known. At this time the other information needed are:

- Ladle thermal status (turn around time and ladle life)

- Estimated alloy additions to be added during tapping

- Estimated tapping time

- Estimated purging time

- Estimated holding time

- Estimated casting time

- Steel quality grade

- Cast section size

For the desired casting temperature the liquid steel temperature just before tapping or just after on-line purging is predicted with the combined help of the developed one dimensional transient heat transfer model and the statistical model (Fig. 15).

During the steelmaking process route the model receives further information about actual events. The liquid steel temperature path is predicted till last the casting, given the measured BOF temperature/measured OLP-out temperature with other useful information (Fig 16). This mathematical model is capable of being activated at any point of time. Thus it is used to update the predicted process and to produce a revised liquid steel temperature path for the remainder of the cast. Based on the predicted steel temperature or temperature path, plant operators take any necessary cor-

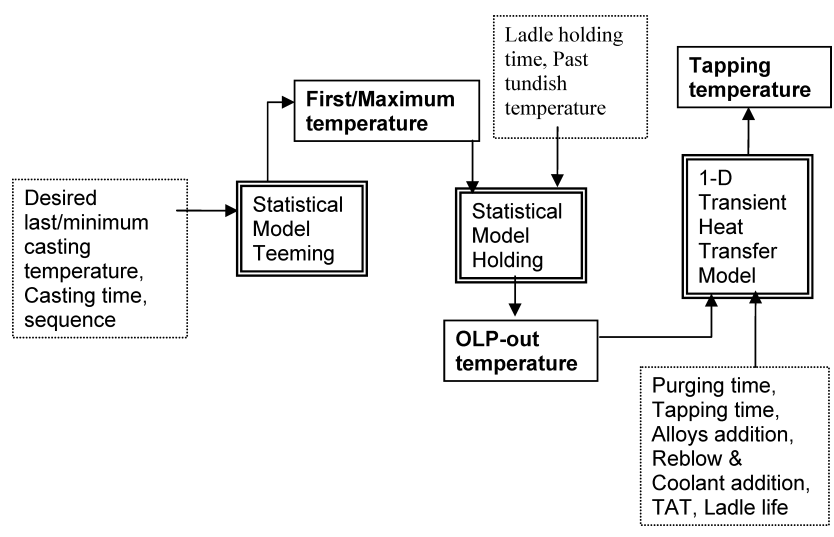

Fig. 14. Configuration of the mathematical model for backward prediction.

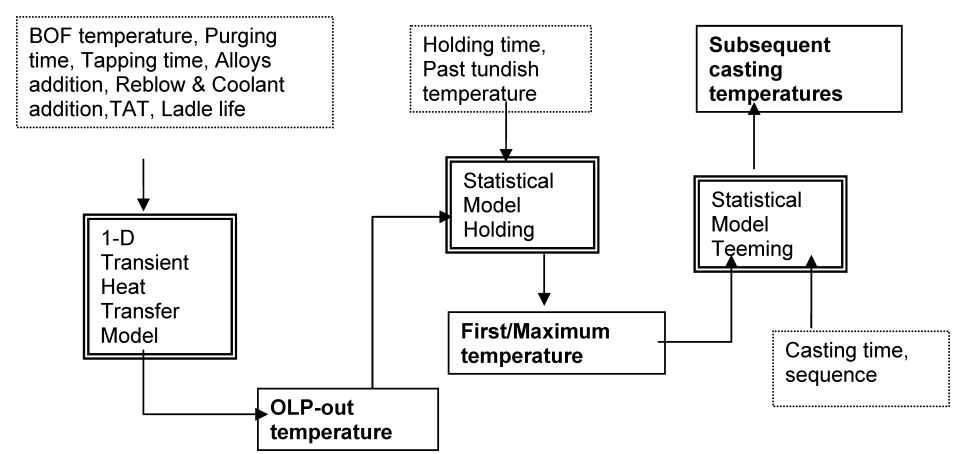

Fig. 13. Configuration of the mathematical model for forward prediction. 


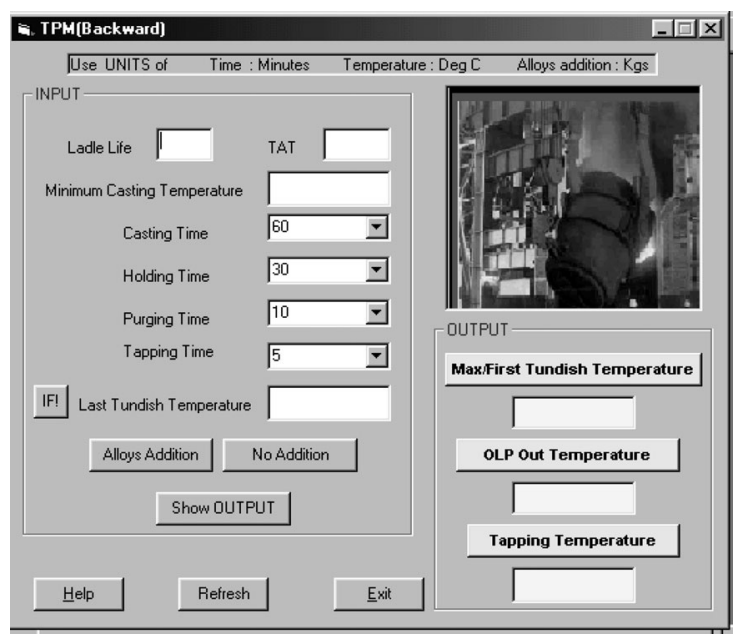

Fig. 15. Input-output screen for backward prediction.

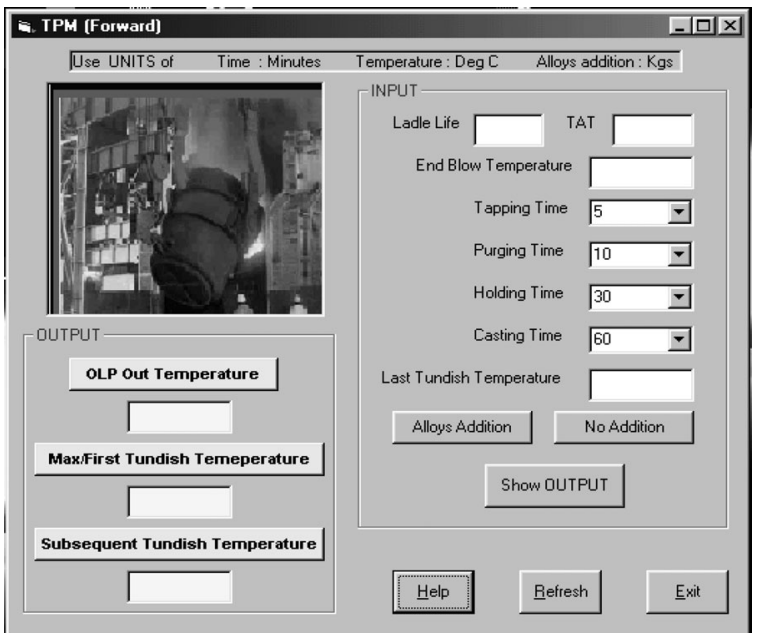

Fig. 16. Input-output screen for forward prediction.

rective action like additional ladle heating and extra/reduced argon stirring to ensure the aim final ladle/tundish temperatures at the casting are achieved.

\section{Conclusion}

- A comprehensive model of simple heat transfer calculations and statistically found relations have been developed to control casting superheat deviations by correctly predicting the target BOF temperature and the likely tundish steel temperature.

- The heat transfer model takes care of the heat losses in the ladle upto secondary metallurgical treatment. Afterwards the non-linearity and complexity of the cooling phenomena are better captured through statistically developed relations.

- The validated thermal model shows that during preheating of the new ladle most of the input energy goes out with the flue gas. About one-third of the heat is lost from the liquid steel through the vessel and falling stream during tapping.

- The simulations give a good approximation of the distribution of total heat loss through the ladle wall, bottom and slag layer. Most of the heat transfer takes place by conduction through the ladle wall.
- The results also show that the cooling effect of turn around time (empty ladle time) on liquid steel is widened as the charged ladle travels onward through the steel making and casting process.

- One important conclusion of the simulations and trials is to emphasize upon the importance of sufficient amount of purging. It is found that the $130 \mathrm{t}$ liquid steel bath does not get homogenized within $2 \mathrm{~min}$ by 400 to $600 \mathrm{~L} / \mathrm{min}$ of argon purging.

- The temperature of the existing liquid steel of last heat in the tundish affects the final temperature of the new liquid steel coming out of the ladle and hence should be taken into account for calculating target BOF temperature for the new heat.

\section{Acknowledgement}

The authors wish to thank the management of LD2\&SC, Tata Steel, India for providing the operating data.

\section{Nomenclature}

$A_{\text {conv }}$ : Contact area of liquid steel with the converter lining $\left(\mathrm{m}^{2}\right)$

$a_{0}, a_{1}, a_{2}, a_{3}, a_{4}, b_{1}, b_{2}, b_{3}, b_{4}: \quad$ Coefficients

$a, b, c, d$ : Constants

$C_{\mathrm{P}}$ : Specific heat of the lining material $\left(\mathrm{J} / \mathrm{kg} \cdot{ }^{\circ} \mathrm{C}\right)$

$C_{\mathrm{pr}}:$ Sp. Heat of refractory lining in converter $\left(\mathrm{J} / \mathrm{kg} \cdot{ }^{\circ} \mathrm{C}\right)$

$\varepsilon:$ Emissivity of steel shell

$\varepsilon_{\mathrm{L}}:$ Emissivity of liquid steel

$F$ : View factor

$h$ : Heat transfer coefficient $\left(\mathrm{W} / \mathrm{m}^{2} \cdot{ }^{\circ} \mathrm{C}\right)$

$k$ : Thermal conductivity of the lining material $(\mathrm{W} / \mathrm{m} \cdot \mathrm{K})$

$K_{\mathrm{r}}$ : Thermal conductivity of the working lining of converter $(\mathrm{W} / \mathrm{m} \cdot \mathrm{K})$

LL : Ladle life

$r$ : Radius of the ladle $(\mathrm{m})$

$r_{\mathrm{i}}$ : Inner radius of the ladle $(\mathrm{m})$

$r_{\mathrm{o}}$ : Outer radius of the ladle $(\mathrm{m})$

$\rho$ : Density $\left(\mathrm{kg} / \mathrm{m}^{3}\right)$

$\rho_{\mathrm{m}}$ : Density of liquid steel $\left(\mathrm{kg} / \mathrm{m}^{3}\right)$

$\rho_{\mathrm{r}}$ : Specific weight of the working lining of the converter

$\sigma:$ Stefan-Boltzman constant

$t$ : Time/(s) (tapping/OL purging/holding/teeming

$t_{\mathrm{m}}$ : Tapping temperature $\left({ }^{\circ} \mathrm{C}\right)$

$t_{\mathrm{rc}}$ : Average temperature of the converter lining $\left({ }^{\circ} \mathrm{C}\right)$

$t_{0}$ : Tapping time (s)

$T$ : Temperature of the lining material $\left({ }^{\circ} \mathrm{C}\right)$

$T_{\mathrm{a}}$ : Ambient temperature $(\mathrm{K})$

$T_{\mathrm{L}}$ : Liquid steel temperature $\left({ }^{\circ} \mathrm{C}\right)$

$T_{\mathrm{s}}$ : Temperature of steel shell $(\mathrm{K})$

$\Delta T_{\mathrm{s}}(t)$ : Temperature difference between top and bottom layer of liquid bath due to thermal stratification

$T_{\mathrm{int}}$ : Initial uniform temperature of liquid steel before holding period

$T_{\text {liq }}$ : Liquidus temperature of a particular grade of steel

$T_{\text {s,avg }}(t)$ : Mean steel temperature in ladle, after holding it for time $t$ 
$T_{\text {past }}:$ Existing steel temperature in tundish

$T_{\text {tunl }}$ : First temperature of the liquid steel in tundish

$T_{\text {OLP-out }}:$ OLP-out temperature

$T_{\mathrm{m}}$ : Teeming temperature

$T_{\text {tund(t) }}:$ Subsequent temperatures

TAT : Turn around time ( $\mathrm{min})$

$z, z_{1}$ : Thickness of bottom wall of the ladle (m)

\section{REFERENCES}

1) T. P. Fredman: Scand. J. Metall., 29 (2000), 232

2) R. Alberny and A. Leclercq: Proc. of Conf. on Mathematical Process Models in Iron and Steelmaking, Metal Soc., London, (1973), 151.

3) M. A. Omotani, L. J. Heaslip and A. Maclean: Iron Steelmaker, (1983), Oct., 29.

4) G. D. Morrow and R. O. Russell: Am. Ceram. Soc. Bull., 64 (1985), No. 7, 1007.

5) J. W. Hlinka, A. W. Cramb and D. H. Bright: 68th Steelmaking Conf. Proc., ISS, Warrendale, PA, (1985), 35.

6) C. E. Tomazin, E. A. Upton and R. A. Wallis: Iron Steelmaker, (1986), Jun, 28

7) A. Gaston, R. Laura and M. Medina: Latin American Applied Research, (1993), 195.

8) F. R. Shklyar, V. M. Malkin, V. A. Korshunov and V. L. Sovetkin: Steel USSR, 21 (1991), 68.

9) A. Zoryk and P. M. Reid: Iron Steelmaker, (1993), Jun, 21.

10) B. Olika and B. Bjorkman: Scand. J. Metall., 22 (1993), 213

11) B. Barber, G. Watson and L. Bowden: Ironmaking Steelmaking, 21 (1994), 150

12) P. R. Austin, S. L. O'Rourke, Q. L. He and A. J. Rex: 75th
Steelmaking Conf. Proc., ISS, Warrendale, PA, (1992), 317.

13) T. P. Fredman and H. Saxen: Metall. Mater. Trans. B, 29B (1998), 651.

14) T. P. Fredman, J. Torrkulla and H. Saxen: Metall. Mater. Trans. B, 30B (1999), 323.

15) C.-E. Grip: 82nd Steelmaking Conf. Proc., ISS, Warrendale, PA, (1999), 405.

16) C.-E. Grip, L. Jonsson and P. G. Jönsson: ISIJ Int., 37 (1997), 1081.

17) B. Olika, Y. Pan, B. Bjorkman and C.E. Grip: Scand. J. Metall., 25 (1996), 18.

18) J. H. Ludley and J. Szekely: J. Iron Steel Inst., (1966), Jan, 12.

19) J. Szekely and R. G. Lee: Trans. Metall. Soc. AIME, 242 (1968), 961.

20) J. Szekely and J. H. Chen: Metall. Trans., 2 (1971), 1189.

21) O. J. Ilegbusi and J. Szekely: Trans. Iron Steel Inst. Jpn., 27 (1987), 563.

22) P. R. Austin, J. M. Camplin, J. Herbertson and I. J. Taggart: ISIJ Int., 32 (1992), 196.

23) V. I. Addes and J. D. Sabol: 79th Steelmaking Conf. Proc., ISS, Warrendale, PA, (1996), 333.

24) J. K. Saha, S. K. Ajmani and A. Chatterjee: Ironmaking Steelmaking, 18 (1991), No. 6, 417.

25) J. G. Henzel and J. Keverian: 19th Proc. of Electrical Furnace Conf., ISS, Warrendale, PA, (1961), 435.

26) The Making, Shaping and Treating of Steel, 10th Ed., United States Steel, (1995), 344.

27) P. R. Austin, J. M. Camplin, J. Herbertson and I. J. Taggart: ISIJ Int., 32 (1992), 196

28) S. Chakraborty and Y. Sahai: Metall. Trans. B, 23 (1992), 135.

29) J. Szekely and J. W. Evans: Trans. Metall. Soc. AIME, 245 (1968), 1149.

30) J. L. Xia and T. Ahokainen: Metall. Mater. Trans. B, 32 (2001), 733. 